\title{
DSP-based Control of the New Current Hystersis PWM Rectifier System
}

\author{
Kexin Wei \\ Tianjin Key Laboratory for Control Theory and \\ Applications in Complicated Systems \\ Tianjin University of Technology \\ Tianjin, China \\ kxwei@tjut.edu.cn
}

\author{
Huaping Li and Shuiming Wang \\ Tianjin Key Laboratory for Control Theory and \\ Applications in Complicated Systems \\ Tianjin University of Technology \\ Tianjin, China \\ hpli1984@163.com
}

\begin{abstract}
In this paper, according to the control requirement and actual project conditions of three-phase high power factor rectifier, the research of low switching losses three-phase PWM rectifier adopts hysteresis current control strategy which bases on load current feed-forward control. The system not only improves the high-frequency switching problem, but also makes that the system has much lower dependence on the PI parameters of the outer-loop voltage regulator than conventional hysteresis current control PWM rectifiers. The system works well even under unbalance power conditions. Both simulated and experimental results confirm the validity of the new control strategy and lower dependence on the PI parameters of the outerloop voltage regulator.
\end{abstract}

Keywords- load current feed-forward control; high power factor; low switching loasses; PI parameters

\section{INTRODUCTION}

Since the PWM control strategy is used in the area of the rectifier, particularly with the development of DSP control devices and the IGBT power devices, hysteresis current control rectifier do attract scholars with it's advantages such as easy to implement, fast dynamic response and low sensitive to the system parameters and the load [1]. However, the traditional hysteresis current control strategy not only led to too high switching frequency of the problem, but also in actual system the voltage outer-loop PI parameters tuning is a major difficulty.

Therefore, this paper from the optimization of the reference current of hysteresis PWM rectifier and to lower the traditional current hysteresis PWM rectifiers of switching frequency point of view, not only proposes a way to limit the maximum switching frequency and reduce switching frequency of changes, but also introduces load current feed-forward control to achieve large-scale increase the three-phase PWM Voltage Rectifier of the outer-loop PI parameters range, making it easier to set more simple and effective.

Using MATLAB / SIMULINK builds the system model structure and the system simulation study. Based on the simulation parameters of physical verification of the results accord with the simulation results, thereby, testing and verifying the control of the superiority of the algorithm.

\section{HYSTERESIS CURRENT CONTROL STRATEGY}

A. Three-phase Voltage Source Rectifier(VSR)mathematical model

Three-phase Voltage Source Rectifier circuit topology shown in Fig. 1:

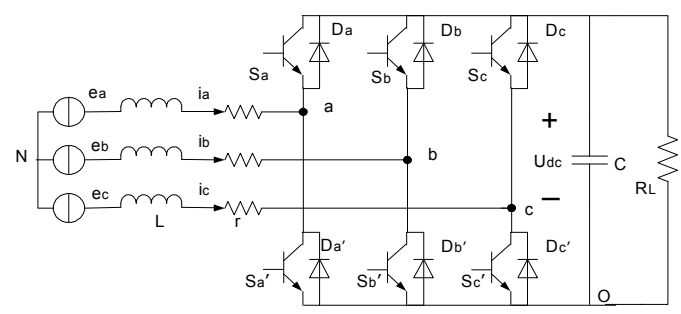

Figure 1. Topology of the three-phase VSR

In the figure above, the definition of unipolar switching function:

$\left\{\begin{array}{l}S m=1\left(S m^{\prime}=0\right), \text { Bridge on the arm turn-on and under the arm cut-off } \\ S m=0\left(S m^{\prime}=1\right), \text { Bridge on the arm turn-off and under the arm cut-on }\end{array}\right.$

After analysis of the available voltage side of the net for the expression:

$u_{m}=\left[s_{m}-\left(s_{a}+s_{b}+s_{c}\right) / 3\right] \times U_{0}$

Where: $\mathrm{m}=\mathrm{a}, \mathrm{b}, \mathrm{c}$

\section{B. Hysteresis Control Strategy in Application of Rectifer}

Hysteresis current control principle is shown in fig. 2. Its core idea is that the real-time actual current signal $i$ be compared to the reference current signal $i^{*}$ in the process of operation: if $i$ is greater than the upper limit $i^{*}+h$, turn on the bridge on the arm to decreased $i$; if $i$ is less than lower limit $i^{*}-h$, turn off the bridge under to increase $i$, where $\mathrm{h}$ is 
defined as the hysteresis width. Through the control method the actual current $i$ can be controlled within a fixed range [2][3].

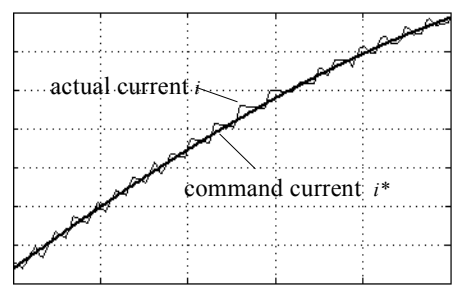

Figure 2. Reference current and the actual current

In the process of hysteresis comparison, the real-time actual current value $i$ is tracking of the reference current signal $i^{*}$ through fluctuations. As $i^{*}$ has the same phase with the input three-phase voltage, with the process of following the tracks of $i^{*}$, the actual current value $i$ achieves to has the same phase as the real input voltage phase, thereby ,achieved the control requirement of high power factor, as shown in fig. 2 .

\section{THE DEFICIENCIES OF TRADITIONAL HYSTERESIS REFERENCE CURRENT}

\section{A. Switching Frequency is not Fixed}

When the width of hysteresis $h$ small enough, it is clear that the actual current is in the closer sine wave current command, but the power devices on-off frequency is dramatically improved, and each cycle the switching frequency is not fixed, resulting in power device too much stress and the system is too high overall switching losses.

\section{B. Reference Current}

In the traditional hysteresis control strategy, took outer-loop PI voltage controller outputs as the base value, and multiplied by the actual voltage measurements as the reference current. This could reduce the complexity of calculation by obtaining the real-time reference current directly, so makes the control system more clear and simple.

However, this control strategy has the following shortcomings:

1. The system extremely dependents on the PI parameters of the outer-loop voltage regulator. When the input voltage or the load have some fluctuations, the formerly PI parameters may not suitable anymore, and the output DC voltage variation is very clear;

2. If the input voltage measurements is not inaccurate (the impact of electromagnetic interference in the actual test is very serious), it will produce a direct impact on the reference current signal, further affect the control effects of the system, while the system has low ability to recover when such deterioration happens in the system;

3. When the input voltage unbalance appear in the system, corresponding three-phase reference current also exist imbalance, which directly worsen output DC voltage and in turn affect the reference current. This will be a vicious circle for control.

\section{IMPROVED CONTROL STRATEGY}

\section{A. Low Switching Frequency to Achieve}

As the three-phase PWM Voltage Source Rectifier equivalent to a combination of step-up chopper electric circuit, which through up and down the bridge arm of the IGBT power devices for high-speed on-off, achieves the main circuit capacitors, inductors of the charge and discharge. Thereby, it achieves the DC output voltage stability control. This may come the law of power device on-off as shown in table 1:

TABLE I. CONTROL TABLE OF SWITCH FUNCTION

\begin{tabular}{c|c|c}
\hline & $\Delta \mathrm{i}_{\mathrm{m}}>\mathrm{h}$ & $\Delta \mathrm{i}_{\mathrm{m}}<-\mathrm{h}$ \\
\hline $\mathrm{i}_{\mathrm{m}}{ }^{*}>0$ & $\mathrm{~S}_{\mathrm{m}}=0\left(\mathrm{~S}_{\mathrm{m}}{ }^{\prime}=1\right)$ & $\mathrm{S}_{\mathrm{m}}=1\left(\mathrm{~S}_{\mathrm{m}}{ }^{\prime}=0\right)$ \\
\hline $\mathrm{i}_{\mathrm{m}}{ }^{*}<0$ & $\mathrm{~S}_{\mathrm{m}}=0\left(\mathrm{~S}_{\mathrm{m}}{ }^{\prime}=1\right)$ & $\mathrm{S}_{\mathrm{m}}=1\left(\mathrm{~S}_{\mathrm{m}}{ }^{\prime}=0\right)$ \\
\hline
\end{tabular}

Voltage power net according to shown in Figure 3 will be zoned, at this time interval identification can be achieved by the power net of synchronized signal. Within the range $I, u_{a}$ 、 $u_{b}$ are Positive, but $u_{c}$ is negative. As the rectifier in a state, side of the power net voltage and current are the same phase. Under these circumstances, there are no current through the $S_{a} 、 S_{b}$ 、 $\mathrm{S}_{\mathrm{c}}{ }^{\prime} 、 \mathrm{D}_{\mathrm{a}^{\prime}} 、 \mathrm{D}_{\mathrm{b}}{ }^{\prime}$ and Dc. If Sc always turn-off, c-phase current only through $\mathrm{Dc}^{\prime}$ continued to flow.

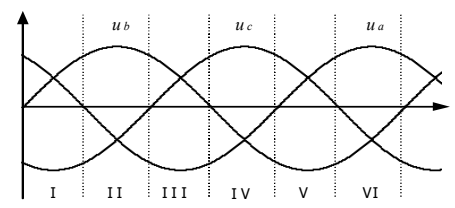

Figure 3. The location division of three phase balanced AC voltage

Only as an example of $\mathrm{i}_{\mathrm{a}} *>0, \Delta \mathrm{i}_{\mathrm{a}}>\mathrm{h}, \mathrm{i}_{\mathrm{b}} *>0, \Delta \mathrm{i}_{\mathrm{b}}>\mathrm{h}$, $\mathrm{i}_{\mathrm{c}} *<0\left(\mathrm{i}_{\mathrm{c}} *=-\mathrm{i}_{\mathrm{a}} *-\mathrm{i}_{\mathrm{b}} *\right)$. According to the above table, a, b twophase bridge on arm cut-off and bridge under arm turn-on. At this point $\mathrm{i}_{\mathrm{a}}, \mathrm{i}_{\mathrm{b}}$ flow $\mathrm{S}_{\mathrm{a}}{ }^{\prime}, \mathrm{S}_{\mathrm{b}}{ }^{\prime}$ to the inductive energy storage, so $i_{L}$ increases. But as the $i_{a} 、 i_{b}$ through $D_{c}$ arising from the continued flow of inhibition, so that the c-phase current tends to refer to current $i_{c}{ }^{*}$. Thereby, the three-phase AC current can effective follow-up the given sine current $\mathrm{i}_{\mathrm{m}} *(\mathrm{~m}=\mathrm{a}, \mathrm{b}, \mathrm{c})$. Other similar cases can also be used to analyze.

In each of the interval, making one bridge arm to maintain a constant switch of state, the two others bridge arm of the switch of state turn-on or turn-off in the light of the switch law as shown in table 1 . Therefore, it can be inferred all the various interval of the switch of turn-on or turn-off law. As follows: Interval I, $\mathrm{S}_{\mathrm{c}}=0$; Interval IV, $\mathrm{S}_{\mathrm{c}}=1$; Interval II, $\mathrm{S}_{\mathrm{b}}=1$; Interval $\mathrm{V}, \mathrm{S}_{\mathrm{b}}=0 ;$ III, $\mathrm{S}_{\mathrm{a}}=0$; Interval VI, $\mathrm{S}_{\mathrm{a}}=1$; Each interval of the rest of two phase switching state of judging based on the above table. 


\section{B. Introduction of the Current Vector Feed-forward}

In process of the three-phase static a-b-c coordinate system transforms into the input $\mathrm{AC}$ voltage-frequency of the baseband the two-phase synchronous rotating $\mathrm{d}-\mathrm{q}$ coordinate system, d-axis is defined as active current component, q-axis is defined as reactive current component. Thus we can get the equation as follow:

$$
\left[\begin{array}{c}
\mathrm{i}_{\mathrm{q}} \\
\mathrm{i}_{\mathrm{d}} \\
i_{0}
\end{array}\right]=R(\theta)\left[\begin{array}{c}
i_{a} \\
i_{b} \\
i_{c}
\end{array}\right]
$$

Simplify as:

$$
I_{d q 0}=R(\theta) I_{a b c}
$$

Where:

$$
R(\theta)=\frac{2}{3}\left[\begin{array}{ccc}
\cos \theta & \cos \left(\theta-120^{\circ}\right) & \cos \left(\theta+120^{\circ}\right) \\
\sin \theta & \sin \left(\theta-120^{\circ}\right) & \sin \left(\theta+120^{\circ}\right) \\
1 / 2 & 1 / 2 & 1 / 2
\end{array}\right]
$$

Use of its anti-transformation, there are:

$I_{a b c}=R^{-1}(\theta) I_{d q 0}$

Where:

$R^{-1}(\theta)=\left[\begin{array}{ccc}\cos \theta & \sin \theta & 1 \\ \cos \left(\theta-120^{\circ}\right) & \sin \left(\theta-120^{\circ}\right) & 1 \\ \cos \left(\theta+120^{\circ}\right) & \sin \left(\theta+120^{\circ}\right) & 1\end{array}\right]$

According to the equation (6) and (7), it is obviously that when given the values of $i_{q} 、 i_{d} 、 i_{0}$, the corresponding three-phase currents $i_{a} 、 i_{b} 、 i_{c}$ will also be determined. When $i_{q} 、 i_{d} 、 i_{0}$ is constant, $i_{a} 、 i_{b} 、 i_{c}$ is not only symmetry of phase sequence, but also changes closely follow the laws of the three-phase sine change [4]. We can control three-phase sine changes by controlling the straight value of active and reactive component in the axe of $\mathrm{d}-\mathrm{q}$ coordinate system, which simplifies the control system .

It is shown that using of two-phase rotating coordinates transforms into the three-phase static coordinate system, the three-phase reference current $i_{a}{ }^{*} 、 i_{b}{ }^{*} 、 i_{c}{ }^{*}$ which is based on the current vector control strategy can easily be calculated. As shown in Fig. 4, taking the DC current ${ }^{i_{R L}}$ as the active current base value, by adding the outer PI voltage regulator outputs as the value of active current component $i_{d} *$, reactive current component $i_{q}{ }^{*}$ and $i_{0}{ }^{*}$ is directly set to 0 .

$i_{d} *=\left(k_{p}+\frac{k_{i}}{S}\right)\left(U_{d c} *-U_{d c}\right)+i_{R l}$
Because of using a load current feed-forward control in the system, the value of outer-loop voltage regulator outputs directly representative of the rate of capacitor voltage changes. This control method greatly increases the linear work range of voltage outer-loop PI regulator.

When the value of $i_{d} *, i_{q} *$ is gained, according to 2-3 coordinate transformation, three-phase reference current which is based on current vector control is calculated.

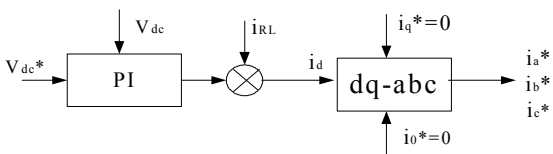

Figure 4. The reference currents based on coordinate transformation

Although this transformation has increased the amount of system computation, the new three-phase reference current obviously has the following advantages :

1. In order to obtain the three-phase current, just directly measures the two system parameters, reducing efficaciously the external interference;

2. Three-phase reference current not only has the same phases with the voltage source, but also has compactness relationship with each other. It changes according to the mechanism of three-phase power supply.

Construction of such a control system, the benefits are obvious: 1. The system has low dependence on the PI parameters of the outer-loop voltage regulator, thus the parameters setting is simple and effective. The output DC voltage can easily achieve to tracking of the reference voltage accurately; 2 . When the system input voltage imbalance exists, the system can effectively reduce the output DC voltage fluctuations. This system shows a stronger ability to against environmental interference; 3 . Decrease of the measurement components, not only improved system stability, but also lower system cost and conducive to the system promotion.

\section{ANALYSIS OF SIMULATION AND EXPERIMENT}

According to the control method proposed above and the control structure as shown in the fig. 5, the system structures and simulation performances is actualized and tested by using MATLAB / SIMULINK. Parameters for the simulation are: the $\mathrm{AC}$ input voltage is $55 \mathrm{~V}$, frequency is $50 \mathrm{~Hz}$; main circuit inductance is $2 \mathrm{mH}$; DC capacitor is $4700 \mu \mathrm{F}$; DC voltage given is $170 \mathrm{~V}$.

This article focuses on three-phase input voltage changes under the control performance. The initial amplitude for the three-phase voltage is $77 \mathrm{~V}$. In the $0.1 \mathrm{~s} \sim 0.2 \mathrm{~s}$, the input voltage from the balance changes into a state of imbalance; And in the $0.2 \mathrm{~s} \sim 0.4 \mathrm{~s}$, input voltage from imbalance jumps into the amplitude of $95 \mathrm{~V}$. Fig. 5,6,7,8 for the input voltage changes in the simulation results. 


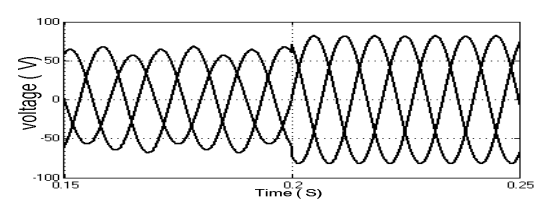

Figure 5. Three-phase input voltage waveform

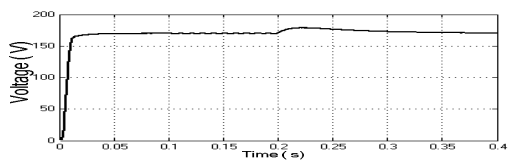

Figure 6. DC output voltage waveform

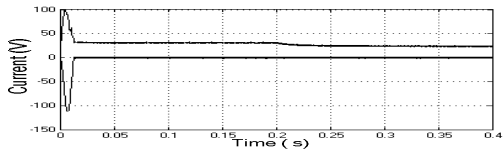

Figure 7. Active current, reactive current

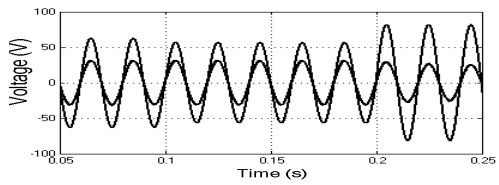

Figure 8. Single-phase input voltage and current waveform

From the simulation can be seen:

Fig. 5 for the three-phase input voltage waveform, it shows the $0.15 \mathrm{~s} \sim 0.25 \mathrm{~s}$ at this stage. The three-phase voltage from the early stage of imbalance changes to $95 \mathrm{~V}$ at $0.2 \mathrm{~s}$. Fig. 6 for the DC output voltage waveform, In the input voltage changing, the system can be adjusted in a short period of time making DC output voltage returning to the given value; Fig. 7 for the actual active current and reactive current waveform. In a dynamic process, the actual active current fast traces the reference current, and the steady-state error is zero. Fig. 8 for the single-phase AC voltage and current waveform, it can see that the current wave appears very good sinusoidal, and at the same time the current and voltage maintain the same phase.

Fig. 9 and Fig.10 shows the single bridge up and down the two power devices switches on-off the control signals. From Fig. 9 and Fig. 10 comparison of the two figures can be seen that the switching signal which bases on switching losses low hysteresis Strategies in a single cycle of $1 / 3$ of the region remains constant, thus effectively reducing the switching losses of the system.

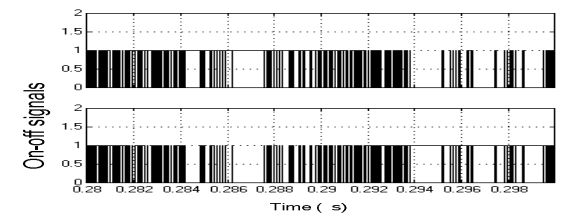

Figure 9. Traditional hysteresis control output signal switch

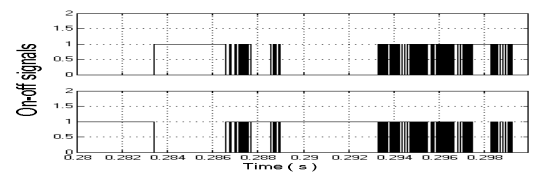

Figure 10. Switching losses low hysteresis control output signal switch

Based on the above analysis, a $12 \mathrm{KW}$ experimental prototype has been used to verify the correctness of the theory analysis and simulation results. Choose SEMIKRON of SKM300GAL128D as main circuit IGBT, and TI 32 highperformance digital signal processor TMS320F2812 is used as control devices for the system. Experimental waveforms are shown in Fig. 11 and Fig. 12.

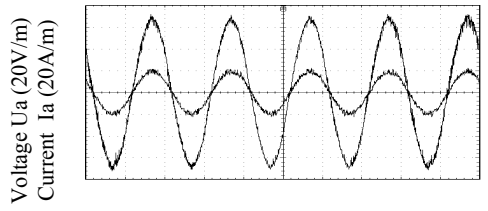

Figure 11. Single-phase voltage and current waveforms

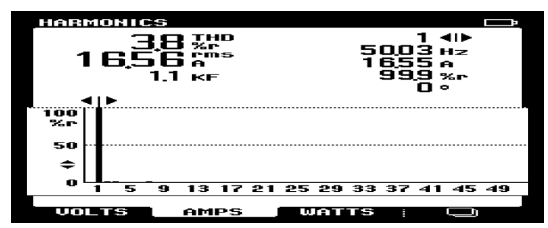

Figure 12. Harmonic content, power factor

\section{CONCLUSINON}

The current hysteresis PWM Rectifier which bases on low switching losses, in the single-cycle limit of different subregional arm of the bridge on-off switch, achieves the low switching losses of control purpose. This system which used the load current feed-forward control and optimized the innerloop reference currents greatly reduces it high degree dependence on the voltage outer-loop PI of parameters. In view of this, the voltage imbalance in the system, it still has a better anti-interference ability to run, and a smaller range of output voltage fluctuations. The experiment results reflect the new hysteresis PWM rectifier has stronger adaptability than traditional hysteresis PWM rectifier under all kinds of circumstance. Simulations and experiments have proved that hysteresis current control strategy which based on low switching losses has a better performance.

\section{REFERENCES}

[1] Zhang Xing, Zhang Chongwei, STUDY ON PWM CONVERTER, China Machine Press, Beijing, 2003.

[2] Yongsug Suh, Thomas A.Lipo, "A Control Scheme of Improved Transient Response for PWM AC/DC Conve-rter under Generalized Unbalanced Operating Conditions", 35th Annual IEEE Power Electronics Specialists Confereence, 2004, PP. 189-195.

[3] Yang Xu, Wang Zhaoan, "A Novel Quasi-Constant Hysteretic PWM Current Mode Contral Approach", Transactions of China Electrotechnical Society, 2003, 18(3), PP. 24-30.

[4] Li Qian, Li Yongdong, "Research on Close-loop Control of Thase PWM Rectifier", Electric Drive, 2007, 37(11), PP. 18-21. 